\title{
Current Concepts in ER Stress-Induced Apoptosis
}

\author{
Susan E Logue, Adrienne M Gorman, Patricia Cleary, Norma Keogh and Afshin Samali* \\ Apoptosis Research Centre, School of Natural Sciences, National University of Ireland Galway, Galway, Ireland
}

\begin{abstract}
Tumour development and progression is associated with cancer cell stress, owing to the rapid proliferative rate of cancer cells. During these processes cancer cells encounter severe cytotoxic conditions such as hypoxia, nutrient deprivation, metabolic changes and acidosis. As a consequence cancer cells must possess high adaptive capabilities in order to contend with such stresses. One of the adaptive responses activated in cancer cells is termed the Unfolded Protein Response (UPR), which is triggered by conditions that adversely affect Endoplasmic Reticulum (ER) homeostasis - a condition referred to as ER stress. Activation of the UPR functions to restore ER homeostasis and confer upon cancer cells a survival advantage. If ER stress is prolonged or too severe signalling switches from pro-survival to pro-death and ER stress-induced apoptosis is triggered. In this article we provide an overview of the current concepts concerning ER stress-induced apoptosis, focussing on the role of ER-localized stress sensors and triggering ER stress-induced apoptosis with particular emphasis on the contribution of Bcl-2 family members.
\end{abstract}

Keywords: Apoptosis; Cancer; Endoplasmic reticulum (ER); ER stress; Unfolded Protein Response (UPR)

\section{Introduction}

The Endoplasmic Reticulum (ER) is a membranous network within cells that is important for several cellular functions including translation and folding of secretory and membrane proteins, lipid biogenesis and sequestration of $\mathrm{Ca}^{2+}[1,2]$. It spans from the nuclear envelope to the plasma membrane. The lumen of the ER contains a plethora of proteins involved in the folding and posttranslational modification of newly synthesised proteins, including chaperones, folding enzymes, oxidizing enzymes, and glycosylating enzymes [1]. Many of these proteins are $\mathrm{Ca}^{2+}$-dependent and require a highly oxidizing environment. ER homeostasis is very sensitive to perturbations in cellular homeostasis and activates an adaptive response known as the unfolded protein response (UPR) when it senses stressful conditions. This can occur in response to conditions such as hypoxia, disturbed $\mathrm{Ca}^{2+}$ homeostasis, accumulation of misfolded proteins, oxidative stress, nutrient deprivation, metabolic changes and acidosis [3].

In this review, we will describe how cells detect ER stress and activate the UPR and how UPR signalling can promote cell recovery or cell death. We also highlight the importance of the intrinsic or mitochondrial apoptotic pathway and Bcl-2 family in the regulation of ER stress-induced cell death. The relevance of these to cancer will be explored briefly.

\section{ER Stress}

To function optimally the ER is dependent on maintaining homeostatic conditions. Any stress which negatively impacts upon energy availability or intracellular $\mathrm{Ca}^{2+}$ levels reduces the ability of the ER to function resulting in the accumulation of unfolded proteins within the ER lumen triggering ER stress. Examples of such stresses include hypoxia, oxidative stress and glucose deprivation. Likewise, stresses which place high protein folding demands on the ER such as inflammation or viral infection can also result in the accumulation of unfolded proteins and ER stress. To counteract ER stress, the cell activates the UPR which initially has a pro-survival role. Three ER localised transmembrane receptors, Pancreatic ER Kinase (PKR)-like ER kinase (PERK), Activating Transcription Factor 6 (ATF6) and Inositol Requiring Enzyme 1 (IRE1 $\alpha$ ) (Figure 1) act as stress sensors and constantly monitor the condition of the ER. Under normal conditions each of these sensors is maintained in an inactive configuration by binding of GRP78 (an ER chaperone protein) to the luminal portion of each receptor (Figure 1). GRP78 has a higher affinity for unfolded proteins and therefore, when they accumulate due to ER stress, GRP78 dissociates from each receptor triggering their activation and induction of the UPR [4].

The primary goal of the UPR is to restore cellular homeostasis by clearing the backlog of unfolded proteins within the ER lumen. UPR signalling shuts down general translation in the cell (to prevent further protein build up), selectively increases the expression of ER chaperone proteins (to aid folding of proteins in the ER lumen) and activates ERAssociated Degradation (ERAD) (which exports misfolded proteins to the cytoplasm where they are degraded by the proteasome). In concert, these processes reduce the load of unfolded proteins and help relieve ER stress. Under circumstances where the level of ER stress is too severe and cannot be resolved, UPR signalling shifts from pro-survival and ER-stress-induced apoptosis ensues [3].

\section{Key mediators of the Unfolded Protein Response PERK}

Following dissociation of GRP78, PERK is activated by dimerization followed by autophosphorylation. One important downstream substrate of active PERK is eukaryotic initiation factor $2 \alpha$ (eIF2 $\alpha$ ) [5] whose phosphorylation on serine 51 inhibits general cap-dependent translation thus reducing further accumulation of proteins within the ER lumen [6]. This block in general translation is important for cell survival as it serves to reduce the continuing build-up of unfolded proteins in the ER thus reducing ER stress. PERK $^{-/}$mouse embryonic

*Corresponding author: Afshin Samali, Apoptosis Research Centre, School of Natural Sciences, National University of Ireland Galway, Galway, Ireland, Tel: +353-91-492440; Fax: +353 91 495504; E-mail: afshin.samali@nuigalway.ie

Received March 30, 2013; Accepted May 22, 2013; Published June 03, 2013

Citation: Logue SE, Gorman AM, Cleary P, Keogh N, Samali A (2013) Current Concepts in ER Stress-Induced Apoptosis. J Carcinogene Mutagene S6: 002. doi:10.4172/2157-2518.S6-002

Copyright: ( 2013 Logue SE, et al. This is an open-access article distributed under the terms of the Creative Commons Attribution License, which permits unrestricted use, distribution, and reproduction in any medium, provided the original author and source are credited. 


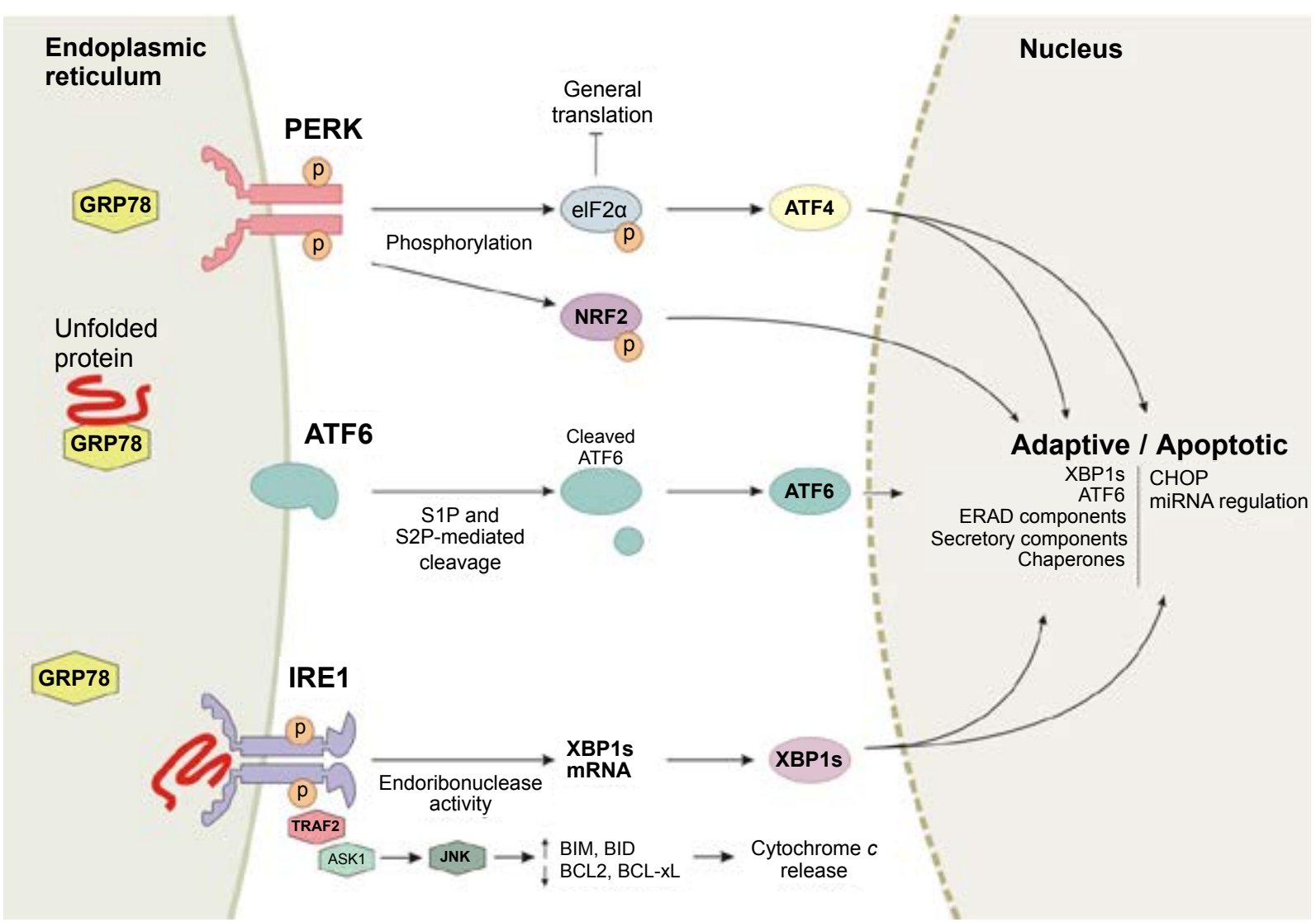

Figure 1: Schematic showing activation of the three arms of the UPR. The three ER stress sensors PERK, IRE1 and ATF6 are kept in their inactive state through interaction with the ER chaperone GRP78 (BiP). In response to accumulating misfolded/unfolded proteins in the ER, GRP78 dissociates from the lumilal domain of these sensors, leading to their activation. The concerted action of PERK, IRE1 and ATF6 activates a transcriptional response which can be adaptive or apoptotic and is essential for cell survival during ER stress. The same transcriptional response also contributes to tumour development and progression.

fibroblasts lack this translational block and as a result are hypersensitive to ER stress [6]. Likewise, knock-in non-phosphorylatable eIF2 $\alpha$ cells also display increased sensitivity to ER stress agents and cell death [7]. This translational block is not absolute as some genes, such as Activating Transcription Factor 4 (ATF4), have an internal ribosome entry site in their 5 ' untranslated region enabling their cap-independent translation [8]. ATF4 is a member of the CCAAT/enhancer binding protein family (C/EBP) of transcription factors. Following its translation, ATF4 translocates to the nucleus where it drives expression of ER chaperone proteins (GRP78 and GRP94), genes involved in amino acid biosynthesis, redox reactions, protein secretion and the pro-apoptotic transcription factor CHOP [9].

\section{ATF6}

Due to the presence of an ER-targeted hydrophobic domain ATF6 is an ER tethered protein. Upon detection of ER stress and dissociation of GRP78, ATF6 translocates to the Golgi apparatus. In the Golgi it is cleaved by 2 proteases, Site- 1 protease $(\mathrm{S} 1 \mathrm{P})$ and Site- 2 protease (S2P) [10]. Active ATF6 is a bZip transcription factor family member which translocates to the nucleus where is drives the expression of chaperone proteins (GRP78, GRP94, Prolyldisulphide Isomerise (PDI)), ER Degradation-Enhancing a-Mannose-Like Protein 1 (EDEM1) and the pro-survival transcription factor X Box-Binding Protein 1 (XBP1) $[11,12]$. ATF6 signalling appears to be predominantly pro-survival with little evidence linking it to cell death. ATF6 has been associated with the down-regulation of Mcl-1 in apoptotic myoblasts during differentiation, however this effect has not been reported in an ER stress specific context [13].

\section{IRE1a}

In a similar mechanism to ATF6 and PERK, IRE1 $\alpha$ is held in an inactivate state through binding to GRP78 and upon dissociation of GRP78, IRE1 $\alpha$ is activated by dimerisation and autophosphorylation. IRE1 $\alpha$ is a bi-functional molecule that has both a serine-threonine protein kinase domain and an endoribonuclease domain [14]. Following its activation, IRE1 $a$ cleaves a 26 nucleotide intron from XBP1 mRNA causing a frameshift enabling translation and generation of a basic leucine zipper family transcription factor, spliced XBP1 (XBP1s) [15]. XBP1s activates the transcription of various proteins involved in the maintenance of ER homeostasis such as ER chaperones (GRP78, ERDj4, HEDJ, and PDI-P5), ER associated degradation (ERAD) components (EDEM, p58 $\left.{ }^{\mathrm{IPK}}\right)$, components of the secretory pathway (SEC23B, SEC24C, SEC61A, SRP54), as well as transcription factors such as CHOP and XBP1 [16,17]. The majority of XBP1s target genes aim to reduce the ER protein load and restore homeostasis. The prosurvival function of IRE1a signalling is further supported in studies examining the temporal activation of UPR signals and overexpression studies. IRE1 $\alpha$ has been identified as one of the first arms switched on during ER stress and to be shut down upon prolonged stress [18]. Furthermore, overexpression of a mutant IRE1a (in which RNase activity can be selectively activated) leads to an enhancement of cell 
survival upon induction of ER stress further underscoring the prosurvival functions of IRE1 $\alpha$ [18].

Recently, the RNase activity of IRE1 $\alpha$ has been linked to a process termed regulated IRE1 $\alpha$-dependent decay of mRNAs (RIDD). While this process was first discovered in D. melanogaster, further studies have identified a mammalian counterpart [19,20]. Although IRE1a RNase activity is required for RIDD to occur, this process is distinct from XBP1 splicing, with RIDD activity being reported to target mRNAs encoding secretory proteins [19]. The importance of RIDD activation is not yet fully understood. However, it is expected to decrease the protein load on the ER helping to restore ER homeostasis. On the other hand extensive or prolonged RIDD activation has recently been associated with increased apoptosis [20]. RIDD is a relatively new discovery in ER stress research and therefore much remains unknown as to its role in ER stress-induced cell death or cancer.

\section{Mechanism of ER Stress-Induced Apoptosis: Role of Bcl-2 Family}

The UPR is predominantly a pro-survival response which offers a window of opportunity to resolve ER stress and return to normal functioning. However, in cases where ER stress is severe or prolonged and the UPR cannot restore homeostasis, signalling switches from prosurvival to pro-apoptotic.

Cell death induced by pro-longed or excessive ER stress predominantly occurs via the intrinsic (or mitochondrial) apoptosis pathway. Release of cytochrome $c$ from the mitochondrial intermembrane space is a key event in intrinsic cell death and is associated with opening of the mitochondrial permeability transition pore and loss of mitochondrial transmembrane potential. Once in the cytosol, cytochrome $c$ recruits pro-caspase- 9 to apoptosis protease activating factor 1 (APAF-1) to form a complex referred to as the apoptosome which enables pro-caspase- 9 activation $[21,22]$. Active caspase- 9 cleaves and activates downstream effector caspases such as caspase-3, which in turn cleave cellular substrates leading to the ordered dismantling of the cell [23]. Activation of the intrinsic apoptotic pathway as a result of unresolved ER stress is mediated by members of the $\mathrm{B}$ cell lymphoma protein 2 (Bcl-2) family which control the release of cytochrome $c$ from the mitochondrial intermembrane space.

The Bcl-2 family of proteins is comprised of pro and anti-apoptotic members with all members containing at least one of the four conserved alpha-helical motifs known as 'Bcl-homology domains' or BH1, BH2, $\mathrm{BH} 3$ and $\mathrm{BH} 4$. Anti-apoptotic family members possess all four $\mathrm{BH}$ domains and include Bcl-xL Bcl-w, the founder protein Bcl-2, Mcl-1 and A1 [24]. The opposing pro-apoptotic proteins can be divided into subfamilies based on which BH-domains they possess. Some, such as $\mathrm{Bak}, \mathrm{Bax}$ and Bok, contain BH-domains 1-3, while others have a $\mathrm{BH} 3$ domain only and are referred to as BH3-only proteins (Bim, Bad, Bik, Bid, Bmf, Hrk, Puma and Noxa). Anti-apoptotic members of the Bcl-2 family interact with pro-apoptotic members neutralising their function. All anti-apoptotic Bcl-2 family members can target Bax while only Bcl-xL and Mcl-1 have been shown to target Bak. Members of the pro-apoptotic $\mathrm{BH} 3$-only family can be subdivided into two distinct groups based on their affinity for multidomain Bcl-2 family proteins. Bid, Bim and Puma interact with and enhance the activity of proapoptotic Bcl-2 proteins, while Bad, Bik, Bmf, Hrk and Noxa interact with anti-apoptotic Bcl-2 proteins to displace Bax and Bak. Once "free" Bax and Bak can translocate to the mitochondrial outer membrane where they homooligomerize to form pores and enable cytochrome $c$ release [25-28].

\section{ER Stress Mediated Regulation of Bcl-2 Family Members}

Regulation of Bcl-2 family members, especially $\mathrm{BH} 3$-only proteins, occurs in response to internal stress signals, including ER stress, and leads to cytochrome $c$ release and caspase activation. The significance of this to ER stress-induced death is clearly illustrated in $\mathrm{Bax}^{-/} / \mathrm{Bak}^{-/-}$cells which display resistance to apoptosis [29]. Additionally, overexpression of anti-apoptotic $\mathrm{Bcl}-2$ or Bcl-xL has been demonstrated to protect cells from ER stress-induced cell death underscoring the importance of Bcl-2 proteins and the intrinsic pathway [30]. In recent years, much focus has been placed on understanding the mechanisms regulating expression of Bcl-2 family proteins during ER stress-induced apoptosis. As a result of this we now have an understanding of how different signalling arms of the UPR can modulate expression of pro- and anti-apoptotic Bcl-2 family members.

CHOP is a bZIP-containing transcription factor that is a common point of convergence for all three arms of the UPR, with binding sites for ATF6, ATF4 and XBP1s present within its promoter. CHOP is primarily considered a pro-apoptotic transcription factor that mediates ER stress induced cell death through the regulation of Bcl-2 family members. Upregulation of the $\mathrm{BH} 3$-only protein Bim has been demonstrated to occur in a CHOP-dependent manner in tunicamycintreated MCF7 cells. Further analysis of this pathway revealed Bim expression was modulated by a combination of CHOP-dependent transcriptional upregulation and post-translational modification by protein phosphatase $2 \mathrm{a}(\mathrm{PP} 2 \mathrm{a})$ increasing protein stability [31]. CHOP has also been reported to interact with FOXO3a to regulate Puma and Bim expression (in neuronal cells) and with AP1 to modulate Puma expression (in hepatocytes) $[32,33]$. CHOP mediated downregulation of Bcl-2 has also been reported as a means by which CHOP can tip the balance in favour of pro-apoptotic Bcl-2 proteins and cell death $[34,35]$.

Upon its activation IRE1 $\alpha$ recruits TNF receptor associated factor 2 (TRAF2) to its cytosolic domain, thus triggering phosphorylation cascades involving ASK1 and culminating in JNK activation. IRE1 $\alpha$ medaited activation of JNK provides a means by which Bcl-2 family member activity can be regulated. JNK-mediated phosphorylation of $\mathrm{Bcl}-2 / \mathrm{Bcl}-\mathrm{xL}$ has been reported to decrease their anti-apoptotic ability while phosphorylation of Bid and Bim by JNK has been demonstrated to increase their pro-apoptotic ability [36-39]. Therefore, IRE1 $\alpha$ mediated JNK activation may represent a mechanism through which IRE1a can manipulate relative levels of pro- and anti-apoptotic Bcl-2 family members thus tipping the balance in favour of apoptosis.

Other transcription factors, not part of the UPR, have also been implicated in ER stress-induced regulation of Bcl-2 family members. For examples, upregulation of the BH3-only proteins Puma and Noxa has been reported to occur during ER stress-induced death in a p53dependent manner [40]. Furthermore, partial suppression of cell death was observed in $\mathrm{p} 53^{-/}$cells and attributed to the reduced expression of Puma and Noxa [41]. The mechanism triggering p53 signalling during ER stress-induced death is currently unknown although $\mathrm{NF} \kappa \mathrm{B}$ activation is thought to play an important role [40]. All three arms of the UPR can be linked in various ways to NFkB activation. For example, PERK-mediated repression of translation causes a reduction in I $\mathrm{B}$ levels (since I $\kappa B$ has a short half-life), thereby relieving the repression on NFKB and allowing it to translocate to the nucleus [42]. IRE1a signalling has been implicated in NFKB activation via its recruitment of IKK through TRAF2, thereby permitting nuclear translocation of NFKB [43]. Finally, ATF6 activation has been implicated in NFkB activation 
in rat renal proximal tubular cells during shiga toxin treatment [42]. NFkB has hundreds of downstream targets and it is likely that some of these are pro-apoptotic such as BH3-only proteins further committing the cell to death.

ER stress regulation of the levels of certain microRNAs (miRNAs), can also influence expression of Bcl-2 family members and hence affect cell fate. Direct regulation of miRNA expression by ER stress sensors especially PERK has been reported. We recently observed that miRNAs belonging to the miR-17-92 cluster and their paralog cluster miR-106b-25 were downregulated during ER stress, in a PERKdependent manner. Further analysis revealed that the PERK-regulated transcription factors NRF2 and ATF4 were responsible for this repression. PERK-dependent induction of ATF4 and phosphorylation of NRF2 leads to repression of the miR-106b-25 cluster, thus removing their inhibition of Bim and pushing the cell towards ER stress-induced cell death [44]. Based on the current literature miRNA regulation may help shift the balance between survival and cell death during ER stress-induced apoptosis. Further studies are required to understand the range of $\mathrm{Bcl}-2$ family members regulated by miRNAs during ER stress-induced apoptosis.

\section{ER Stress and Cancer}

Cancer cells are uniquely dependent on UPR signalling to enable their survival within the tumour microenvironment especially in the early stages of tumourigenesis before sufficient vascularisation has occurred. The tumour microenvironment is characterised by conditions such as hypoxia, low nutrients and $\mathrm{pH}$ fluctuations, all potent inducers of ER stress. To survive under these conditions cancer cells must initiate adaptive strategies. To this end, elevated expression and dependence on various ER chaperone proteins and arms of the UPR has been observed, and ER stress and the UPR have been linked to the development and progression of cancer. In fact, the UPR is currently emerging as a viable therapeutic target for the treatment of cancer [45].

Numerous studies have shown that GRP78 is overexpressed in many cancers, including prostate, breast and lung cancers [46-53]. Jamora and colleagues have demonstrated cells incapable of inducing GRP78 are incapable of tumour formation [54], thus illustrating the importance of GRP78 in tumour development. Additionally, expression of GRP78 was found to correlate with high levels of proliferation in glioma cells while knockdown decreased the cells' proliferative capacity [55]. Upregulation of GRP78 expression has been linked to protection of dormant tumour cells against drug toxicity, possibly via reduced Bax activation [56]. By upregulating GRP78 expression cancer cells may simply be increasing the protein-folding capacity of the ER, thereby avoiding the induction of ER stress and cell death.

The IRE1 $\alpha / X B P 1 s$ branch of the UPR has also been implicated in cancer cell survival and proliferation. Xenograft models have clearly highlighted the importance of IRE1 $\alpha / X B P 1 s$ to tumour development. Injection of $\mathrm{XBP}^{-1}$ cells into immune-compromised mice failed to result in tumour formation as compared to their wild type counterparts [57]. Sustained IRE1 $\alpha$ signalling and selective XBP1s overexpression has also been linked to increased cell proliferation, while specific knockdown of XBP1s decreases the proliferative capacity of cells. The mechanism of how IRE1a/XBP1s signalling can influence cell proliferation has not yet been fully elucidated although increased expression of cyclin A1 has been reported [58]. Basal overexpression of $\mathrm{XBP} 1 \mathrm{~s}$ has been reported across a range of cancer types including breast cancer, multiple myeloma and hepatocellular cancer [59-61]. Studies by Carassaco and colleagues reported XBP1s-overexpressing mice induced neoplastic transformation of plasma cells and spontaneously developed multiple myeloma [62]. Numerous studies examining gene regulation in the development of breast cancer have shown increased expression of XBP1 mRNA. Moreover, tissue microarray studies found XBP1s positively correlated with aggressive, highly proliferative, and/ or high grade mammary tumours [63] suggesting that XBP1s may be important in the progression of breast cancer.

In contrast, xenograft models using PERK ${ }^{-1}$ cells demonstrated tumour establishment (unlike IRE1 $\alpha^{-/}$cells) [64] but reported an attenuated growth rate and increased apoptosis rate compared to wild type cells highlighting a need for PERK signalling in tumour development.

\section{Targeting the UPR}

As previously described the UPR has both pro-survival and prodeath potential. Therefore, targeting this response either by attenuating the adaptive arm or enhancing pro-death signalling may have clinical potential in the treatment of cancer. To date, drug development targeting the UPR has mainly focused on the inhibition of pro-survival IRE1a signals. This has lead to the development of compounds such as STF- 083010 and MKC-3646, which act by inhibiting the catalytic core of the RNase domain $[65,66]$. Directly targeting the endoribonuclease domain of IRE1 1 blocks its ability to cleave XBP1 mRNA therefore reducing levels of the pro-survival transcription factor XBP1s. Attenuating signalling via this arm of the UPR, is thought to reduce prosurvival responses and push the cell in the direction of death. Indeed, recent work by Mimura and colleagues has highlighted the therapeutic potential of limiting XBP1 cleavage in multiple myeloma (MM) cells [67]. Xenograft mouse models of MM displayed a significant decrease in tumour volume following treatment with MKC-3646 compared to vehicle alone [66]. Increased levels of heat shock proteins is frequently reported in cancer [68]. Recently, Hsp72 demonstrated to interact with IRE1 $\alpha$ enhancing its activity and splicing of XBP1 [69], while Hsp90 association is required for IRE1 $\alpha$ stability and activation [70]. Therefore, specific targeting of Hsps for example, Hsp72 or Hsp90, by compounds such as MAL3-101, 17-AAG and radicicol may also help counteract IRE1 $\alpha$ pro-survival signalling and enhance cell death. In fact, 17-AAG in combination with MKC-3646 had increased cytotoxicity when compared to either treatment alone in RPMI 8226 and INA6 MM cell lines [66].

PERK signalling contributes to pro-survival UPR responses by attenuating cap-dependent translation through the phosphorylation of eIF2 $\alpha$, thus preventing further protein accumulation in the ER. GSK2656157, an ATP competitive inhibitor of PERK catalytic activity, limits the ability of PERK to block translation enhancing cell death Recent in vivo xenograft studies, using GSK2656157, have reported diminished growth in $\mathrm{MM}$ and pancreatic-derived tumours, thus highlighting the clinical potential of targeting PERK as an anti-cancer treatment [71].

Alternatively, rather than suppress the adaptive phase of the UPR another approach is to enhance the level of ER stress pushing the cell towards cell death. Proteasome inhibitors, such as Bortezomib, prevent the degradation of damaged/misfolded proteins increasing the level of ER stress and committing the cell to death. Bortezomib has been successfully used as a single agent therapy but has also been combined with an inhibitor of IRE1a endoribonuclease activity providing an effective treatment where ER stress is increased and pro-survival IRE1a signals inhibited. Alternative strategies for increasing ER stress levels 
include inhibitors of ERAD pathway. p97ATPase is involved in ERAD retrotranslocation and the ubiquitin fusion degradation pathway, inhibitors such as Eeyarestatin and DBeQ can block p97ATPase activity with the latter reported to induce rapid caspase activation and death in Hela cells [72].

Overall, the UPR presents itself as a clinically relevant and druggable target as it is often the deciding factor between cell survival and cell death. Manipulation of these processes is only starting to be exploited in cancer treatment with initial studies in MM looking promising; however other cancers also need to be explored for drug development to fully exploit this mechanism in cancer therapy.

\section{Conclusion}

ER stress is implicated in many diseases such as cardiovascular disease, metabolic diseases, neurodegenerative diseases including Alzheimer's disease and cancer. The identification of the important players and mediators of these diseases presents promising drug targets and potential therapeutic strategies. The targeting of the UPR and ER stress is a promising area in anti-cancer therapies, however there are some challenges associated with their use as drug targets. A therapeutic window in which it is possible to selectively target and kill the cancer cells with an increased UPR without affecting the normal cells is the most desirable scenario for treatment. Another challenge is the need for the development of suitable UPR biomarkers that can be used to determine the role of the UPR in predicting disease-free survival in patients [73]. In 2008 Davies and colleagues measured XBP1s mRNA levels by Q-PCR in breast cancer patients during treatment with tamoxifen and found that those patients with elevated XBP1s levels had a significantly worse clinical outcome compared to their counterparts with lower XBP1s expression [63]. This presents the exciting possibility of using XBP1s as a potential biomarker in breast cancer. It has been established that the UPR is essential for tumourigenesis and in establishing a suitable tumour microenvironment, but relatively little is known of the UPR's involvement in maintaining already-formed tumours. As cancer patients will usually not present to a clinician until the tumour has been established it would be advantageous to elucidate the UPR's role in already-formed tumours. This is one possible future direction for studies into ER stress, the UPR and their role in cancer.

\section{Acknowledgements}

Our research is supported by grants from Science Foundation Ireland (09/ RFP/BIC2371; 09/RFP/BMT2153), Breast Cancer Campaign (2010NovPR13; 2008NovPhD21). P Cleary is funded by an Irish Cancer Society Scholarship (CRS11CLE).

\section{Declaration of conflict of Interest}

A Samali is co-founder and director of Aquila Bioscience Limited.

\section{References}

1. Braakman I, Bulleid NJ (2011) Protein folding and modification in the mammalian endoplasmic reticulum. Annu Rev Biochem 80: 71-99.

2. Arbabian A, Brouland JP, Gélébart $P$, Kovàcs T, Bobe R, et al. (2011) Endoplasmic reticulum calcium pumps and cancer. Biofactors 37: 139-149.

3. Szegezdi E, Logue SE, Gorman AM, Samali A (2006) Mediators of endoplasmic reticulum stress-induced apoptosis. EMBO Rep 7: 880-885.

4. Bertolotti A, Zhang Y, Hendershot LM, Harding HP, Ron D (2000) Dynamic interaction of $\mathrm{BiP}$ and $\mathrm{ER}$ stress transducers in the unfolded-protein response. Nat Cell Biol 2: 326-332.

5. Donnelly N, Gorman AM, Gupta S, Samali A (2013) The elF2ît kinases: their structures and functions. Cell Mol Life Sci .

6. Harding HP, Zhang Y, Ron D (1999) Protein translation and folding are coupled by an endoplasmic-reticulum-resident kinase. Nature 397: 271-274.
7. Scheuner D, Song B, McEwen E, Liu C, Laybutt R, et al. (2001) Translationa control is required for the unfolded protein response and in vivo glucose homeostasis. Mol Cell 7: 1165-1176.

8. Lu PD, Harding HP, Ron D (2004) Translation reinitiation at alternative open reading frames regulates gene expression in an integrated stress response. $J$ Cell Biol 167: 27-33.

9. Harding HP, Zhang Y, Zeng H, Novoa I, Lu PD, et al. (2003) An integrated stress response regulates amino acid metabolism and resistance to oxidative stress. Mol Cell 11: 619-633.

10. Ye J, Rawson RB, Komuro R, Chen X, Davé UP, et al. (2000) ER stress induces cleavage of membrane-bound ATF6 by the same proteases that process SREBPs. Mol Cell 6: 1355-1364.

11. Adachi Y, Yamamoto K, Okada T, Yoshida H, Harada A, et al. (2008) ATF6 is a transcription factor specializing in the regulation of quality control proteins in the endoplasmic reticulum. Cell Struct Funct 33: 75-89.

12. Yoshida H, Okada T, Haze K, Yanagi H, Yura T, et al. (2000) ATF6 activated by proteolysis binds in the presence of NF-Y (CBF) directly to the cis-acting element responsible for the mammalian unfolded protein response. Mol Cell Biol 20: 6755-6767.

13. Morishima N, Nakanishi K, Nakano A (2011) Activating transcription factor-6 (ATF6) mediates apoptosis with reduction of myeloid cell leukemia sequence 1 (Mcl-1) protein via induction of WW domain binding protein 1. J Biol Chem 286: 35227-35235.

14. Wang XZ, Harding HP, Zhang Y, Jolicoeur EM, Kuroda M, et al. (1998) Cloning of mammalian Ire1 reveals diversity in the ER stress responses. EMBO J 17 5708-5717.

15. Yoshida $\mathrm{H}$, Matsui T, Yamamoto A, Okada T, Mori K (2001) XBP1 mRNA is induced by ATF6 and spliced by IRE1 in response to ER stress to produce a highly active transcription factor. Cell 107: 881-891.

16. Lee AH, Iwakoshi NN, Glimcher LH (2003) XBP-1 regulates a subset of endoplasmic reticulum resident chaperone genes in the unfolded protein response. Mol Cell Biol 23: 7448-7459.

17. Shaffer AL, Shapiro-Shelef M, Iwakoshi NN, Lee AH, Qian SB, et al. (2004) XBP1, downstream of Blimp-1, expands the secretory apparatus and othe organelles, and increases protein synthesis in plasma cell differentiation. Immunity 21: 81-93.

18. Lin JH, Li H, Yasumura D, Cohen HR, Zhang C, et al. (2007) IRE1 signaling affects cell fate during the unfolded protein response. Science 318: 944-949.

19. Hollien J, Weissman JS (2006) Decay of endoplasmic reticulum-localized mRNAs during the unfolded protein response. Science 313: 104-107.

20. Han D, Lerner AG, Vande Walle L, Upton JP, Xu W, et al. (2009) IRE1alpha kinase activation modes control alternate endoribonuclease outputs to determine divergent cell fates. Cell 138: 562-575.

21. Zou H, Henzel WJ, Liu X, Lutschg A, Wang X (1997) Apaf-1, a human protein homologous to $C$. elegans CED-4, participates in cytochrome c-dependen activation of caspase-3. Cell 90: 405-413.

22. Zou H, Li Y, Liu X, Wang X (1999) An APAF-1.cytochrome c multimeric complex is a functional apoptosome that activates procaspase-9. J Biol Chem 274: $11549-11556$

23. Samali A, Zhivotovsky B, Jones D, Nagata S, Orrenius S (1999) Apoptosis: cell death defined by caspase activation. Cell Death Differ 6: 495-496.

24. Youle RJ, Strasser A (2008) The BCL-2 protein family: opposing activities that mediate cell death. Nat Rev Mol Cell Biol 9: 47-59.

25. Antonsson B, Montessuit S, Sanchez B, Martinou JC (2001) Bax is present as a high molecular weight oligomer/complex in the mitochondrial membrane of apoptotic cells. J Biol Chem 276: 11615-11623.

26. Hsu YT, Wolter KG, Youle RJ (1997) Cytosol-to-membrane redistribution of Bax and Bcl-X(L) during apoptosis. Proc Natl Acad Sci U S A 94: 3668-3672.

27. Wolter KG, Hsu YT, Smith CL, Nechushtan A, Xi XG, et al. (1997) Movement of Bax from the cytosol to mitochondria during apoptosis. J Cell Biol 139: 1281 1292

28. Szegezdi E, Macdonald DC, Ní Chonghaile T, Gupta S, Samali A (2009) Bcl-2 family on guard at the ER. Am J Physiol Cell Physiol 296: C941-953. 
29. Wei MC, Zong WX, Cheng EH, Lindsten T, Panoutsakopoulou V, et al. (2001) Proapoptotic BAX and BAK: a requisite gateway to mitochondrial dysfunction and death. Science 292: 727-730.

30. Distelhorst CW, McCormick TS (1996) Bcl-2 acts subsequent to and independent of $\mathrm{Ca} 2+$ fluxes to inhibit apoptosis in thapsigargin- and glucocorticoid-treated mouse lymphoma cells. Cell Calcium 19: 473-483.

31. Puthalakath H, O'Reilly LA, Gunn P, Lee L, Kelly PN, et al. (2007) ER stress triggers apoptosis by activating BH3-only protein Bim. Cell 129: 1337-1349.

32. Ghosh AP, Klocke BJ, Ballestas ME, Roth KA (2012) CHOP potentially cooperates with FOXO3a in neuronal cells to regulate PUMA and BIM expression in response to ER stress. PLoS One 7: e39586.

33. Cazanave SC, Elmi NA, Akazawa Y, Bronk SF, Mott JL, et al. (2010) CHOP and AP-1 cooperatively mediate PUMA expression during lipoapoptosis. Am J Physiol Gastrointest Liver Physiol 299: G236-G243.

34. McCullough KD, Martindale JL, Klotz LO, Aw TY, Holbrook NJ (2001) Gadd153 sensitizes cells to endoplasmic reticulum stress by down-regulating $\mathrm{Bcl} 2$ and perturbing the cellular redox state. Mol Cell Biol 21: 1249-1259.

35. Matsumoto M, Minami M, Takeda K, Sakao Y, Akira S (1996) Ectopic expression of CHOP (GADD153) induces apoptosis in M1 myeloblastic leukemia cells. FEBS Lett 395: 143-147.

36. Maundrell K, Antonsson B, Magnenat E, Camps M, Muda M, et al. (1997) Bcl-2 undergoes phosphorylation by C-Jun $\mathrm{N}$-terminal kinase/stress-activated protein kinases in the presence of the constitutively active GTP-binding protein Rac1. J Biol Chem 272: 25238-25242.

37. Lei K, Davis RJ (2003) JNK phosphorylation of Bim-related members of the Bcl2 family induces Bax-dependent apoptosis. Proc Natl Acad Sci U S A 100: 2432-2437.

38. Donovan N, Becker EB, Konishi Y, Bonni A (2002) JNK phosphorylation and activation of $B A D$ couples the stress-activated signaling pathway to the cell death machinery. J Biol Chem 277: 40944-40949.

39. Yamamoto K, Ichijo H, Korsmeyer SJ (1999) BCL-2 is phosphorylated and inactivated by an ASK1/Jun N-terminal protein kinase pathway normally activated at G(2)/M. Mol Cell Biol 19: 8469-8478.

40. Lin WC, Chuang YC, Chang YS, Lai MD, Teng YN, et al. (2012) Endoplasmic reticulum stress stimulates p53 expression through NF-Î ${ }^{\circ} \mathrm{B}$ activation. PLoS One 7: e39120.

41. Deng J, Lu PD, Zhang Y, Scheuner D, Kaufman RJ, et al. (2004) Translational repression mediates activation of nuclear factor kappa $B$ by phosphorylated translation initiation factor 2. Mol Cell Biol 24: 10161-10168.

42. Yamazaki H, Hiramatsu N, Hayakawa K, Tagawa Y, Okamura M, et al. (2009) Activation of the Akt-NF-kappaB pathway by subtilase cytotoxin through the ATF6 branch of the unfolded protein response. J Immunol 183: 1480-1487.

43. Kaneko M, Niinuma $Y$, Nomura $Y$ (2003) Activation signal of nuclear factorkappa $B$ in response to endoplasmic reticulum stress is transduced via IRE1 and tumor necrosis factor receptor-associated factor 2. Biol Pharm Bull 26 931-935.

44. Gupta S, Read DE, Deepti A, Cawley K, Gupta A, et al. (2012) Perk-dependent repression of miR-106b-25 cluster is required for ER stress-induced apoptosis. Cell Death Dis 3: e333.

45. Healy SJ, Gorman AM, Mousavi-Shafaei P, Gupta S, Samali A (2009) Targeting the endoplasmic reticulum-stress response as an anticancer strategy. Eur J Pharmacol 625: 234-246.

46. Fernandez PM, Tabbara SO, Jacobs LK, Manning FC, Tsangaris TN, et al. (2000) Overexpression of the glucose-regulated stress gene GRP78 in malignant but not benign human breast lesions. Breast Cancer Res Treat 59 : 15-26.

47. Lee AS (2007) GRP78 induction in cancer: therapeutic and prognostic implications. Cancer Res 67: 3496-3499.

48. Li J, Lee AS (2006) Stress induction of GRP78/BiP and its role in cancer. Curr Mol Med 6: 45-54.

49. Uramoto H, Sugio K, Oyama T, Nakata S, Ono K, et al. (2005) Expression of endoplasmic reticulum molecular chaperone Grp78 in human lung cancer and its clinical significance. Lung Cancer 49: 55-62.

50. Wang Q, He Z, Zhang J, Wang Y, Wang T, et al. (2005) Overexpression of endoplasmic reticulum molecular chaperone GRP94 and GRP78 in human lung cancer tissues and its significance. Cancer Detect Prev 29: 544-551.

51. Wang XP, Qiu FR, Liu GZ, Chen RF (2005) Correlation between clinicopathology and expression of heat shock protein 70 and glucose-regulated protein 94 in human colonic adenocarcinoma. World J Gastroenterol 11: 1056-1059.

52. Zheng HC, Takahashi H, Li XH, Hara T, Masuda S, et al. (2008) Overexpression of GRP78 and GRP94 are markers for aggressive behavior and poor prognosis in gastric carcinomas. Hum Pathol 39: 1042-1049.

53. Dong D, Ni M, Li J, Xiong S, Ye W, et al. (2008) Critical role of the stress chaperone GRP78/BiP in tumor proliferation, survival, and tumor angiogenesis in transgene-induced mammary tumor development. Cancer Res 68: 498-505.

54. Jamora C, Dennert G, Lee AS (1996) Inhibition of tumor progression by suppression of stress protein GRP78/BiP induction in fibrosarcoma B/C10ME. Proc Natl Acad Sci USA 93: 7690-7694.

55. Pyrko P, Schönthal AH, Hofman FM, Chen TC, Lee AS (2007) The unfolded protein response regulator GRP78/BiP as a novel target for increasing chemosensitivity in malignant gliomas. Cancer Res 67: 9809-9816.

56. Ranganathan AC, Zhang L, Adam AP, Aguirre-Ghiso JA (2006) Functiona coupling of p38-induced up-regulation of BiP and activation of RNA-dependent protein kinase-like endoplasmic reticulum kinase to drug resistance of dormant carcinoma cells. Cancer Res 66: 1702-1711.

57. Romero-Ramirez L, Cao H, Nelson D, Hammond E, Lee AH, et al. (2004) XBP1 is essential for survival under hypoxic conditions and is required for tumor growth. Cancer Res 64: 5943-5947.

58. Thorpe JA, Schwarze SR (2010) IRE1alpha controls cyclin A1 expression and promotes cell proliferation through XBP-1. Cell Stress Chaperones 15: 497508

59. Fujimoto T, Onda M, Nagai H, Nagahata T, Ogawa K, et al. (2003) Upregulation and overexpression of human X-box binding protein $1(\mathrm{hXBP}-1)$ gene in primary breast cancers. Breast Cancer 10: 301-306.

60. Munshi NC, Hideshima T, Carrasco D, Shammas M, Auclair D, et al. (2004) Identification of genes modulated in multiple myeloma using genetically identical twin samples. Blood 103: 1799-1806.

61. Shuda M, Kondoh N, Imazeki N, Tanaka K, Okada T, et al. (2003) Activation of the ATF6, XBP1 and grp78 genes in human hepatocellular carcinoma: a possible involvement of the ER stress pathway in hepatocarcinogenesis. J Hepatol 38: 605-614

62. Carrasco DR, Sukhdeo K, Protopopova M, Sinha R, Enos M, et al. (2007) The differentiation and stress response factor XBP-1 drives multiple myeloma pathogenesis. Cancer Cell 11: 349-360

63. Davies MP, Barraclough DL, Stewart C, Joyce KA, Eccles RM, et al. (2008) Expression and splicing of the unfolded protein response gene XBP-1 are significantly associated with clinical outcome of endocrine-treated breast cancer. Int J Cancer 123: 85-88.

64. Bi M, Naczki C, Koritzinsky M, Fels D, Blais J, et al. (2005) ER stress-regulated translation increases tolerance to extreme hypoxia and promotes tumor growth. EMBO J 24: 3470-3481.

65. Papandreou I, Denko NC, Olson M, Van Melckebeke H, Lust S, et al. (2011) Identification of an Ire1alpha endonuclease specific inhibitor with cytotoxic activity against human multiple myeloma. Blood 117: 1311-1314.

66. Mimura N, Fulciniti M, Gorgun G, Tai YT, Cirstea D, et al. (2012) Blockade of XBP1 splicing by inhibition of IRE1 $1 \pm$ is a promising therapeutic option in multiple myeloma. Blood 119: 5772-5781.

67. Mimura N, Fulciniti M, Gorgun G, Tai YT, Cirstea D, et al. (2012) Blockade of XBP1 splicing by inhibition of IRE1 1 Is a promising therapeutic option in multiple myeloma. Blood 119: 5772-5781.

68. Westerheide SD, Morimoto RI (2005) Heat shock response modulators as therapeutic tools for diseases of protein conformation. J Biol Chem 280: 33097 33100.

69. Gupta S, Deepti A, Deegan S, Lisbona F, Hetz C, et al. (2010) HSP72 protects cells from ER stress-induced apoptosis via enhancement of IRE1alpha-XBP1 signaling through a physical interaction. PLoS Biol 8: e1000410.

70. Marcu MG, Doyle M, Bertolotti A, Ron D, Hendershot L, et al. (2002) Heat shock protein 90 modulates the unfolded protein response by stabilizing IRE1alpha. Mol Cell Biol 22: 8506-8513. 
Citation: Logue SE, Gorman AM, Cleary P, Keogh N, Samali A (2013) Current Concepts in ER Stress-Induced Apoptosis. J Carcinogene Mutagene S6: 002. doi:10.4172/2157-2518.S6-002

Page 7 of 7

71. Atkins C, Liu Q, Minthorn E, Zhang SY, Figueroa DJ, etal. (2013) Characterization of a novel PERK kinase inhibitor with antitumor and antiangiogenic activity. Cancer Res 73: 1993-2002.

72. Chou TF, Brown SJ, Minond D, Nordin BE, Li K, et al. (2011) Reversible inhibitor of $\mathrm{p} 97, \mathrm{DBeQ}$, impairs both ubiquitin-dependent and autophagic protein clearance pathways. Proceedings of the National Academy of Sciences 108: 4834-4839.

73. Suh DH, Kim MK, Kim HS, Chung HH, Song YS (2012) Unfolded protein response to autophagy as a promising druggable target for anticancer therapy. Ann N Y Acad Sci 1271: 20-32.
This article was originally published in a special issue, Apoptosis handled by Editor(s). Dr. Nancy Turner, Texas A\&M University, USA 